\title{
Perioperative Transfusion is Related to the Length of Hospital Stays in Primary Liver Cancer Patients
}

\author{
Qi Qi* \\ Xuemeng Qian* \\ Xinfang Zhu \\ Jiajing Cai $(\mathbb{D}$ \\ Rong Xia \\ Qi Zhang
}

Department of Transfusion Medicine, Huashan Hospital, Fudan University, Shanghai, 200040, People's Republic of China

*These authors contributed equally to this work

Correspondence: Qi Zhang; Rong Xia Department of Transfusion Medicine, Huashan Hospital, Fudan University, 12 Urumqi Middle Road, Shanghai, 200040,

People's Republic of China

Email friday045I@I63.com;

xiarongcn@I26.com
Purpose: Blood loss may be corrected with red blood cell transfusion, but may ultimately contribute to negative impacts. This study was a retrospective analysis to assess the impact of perioperative blood transfusion on hospital stay days in liver cancer patients.

Methods: We retrospectively examined data from patients with primary liver cancer who underwent curative resection. Patients were divided into perioperative blood transfusion (PBT) and non-PBT groups. Data were given as means and SDs for continuous variables and as counts and percentage for categorical variables. The correlation between blood transfusion and hospital stay days was analyzed by Fisher's exact test. Multivariable logistic regression analyses were used to identify independent predictors of length of hospital stays. Results: Totally 206/1031 patients (20.3\%) were given perioperative transfusion. The mean length of hospital stay was 17.8 days in PBT and 13.9 days in non-PBT groups. Our multivariable logistic regression showed transfusion, total bilirubin, indirect bilirubin, and the ratio of albumin to bilirubin were all indicators of the length of hospital stay days. Perioperative transfusion was also associated with prolonged length of hospital stays $(95 \%$ CI: $0.395-0.811, \mathrm{p}=0.002$ ). Transfusion also affected intrinsic coagulation factors (activated partial thromboplastin time, fibrinogen, platelet), inflammatory index (neutrocyte to lymphocyte ratio, monocyte), albumin and bilirubin levels.

Conclusion: Perioperative transfusion of blood was associated with a significantly increased length of hospital stays probably via changing intrinsic coagulation and inflammatory factors and bilirubin levels in plasma.

Keywords: primary liver cancer, transfusion, length of hospital stays, bilirubin, coagulation factor, inflammatory factor

\section{Introduction}

It has been reported that millions of units of blood products are transfused annually. ${ }^{1}$ Complications are more likely to take place after transfusion of blood products ${ }^{2}$ and transfusion can significantly increase the risk of morbidity and death in critically ill patients. ${ }^{3}$ Previous studies suggested that the storage time of red blood cells (RBCs) may lead to immunosuppression. ${ }^{4,5}$ RBCs undergo morphologic and functional changes during the duration for storage 6 (what is called "storage lesions"), including imbalance of the cell membrane expression of CD47 and phosphatidylserine, which can contribute to activate the immune system. ${ }^{7}$ Moreover, during storage, cytokines and other immunomodulatory substances accumulate in the supernatant and trigger the activation of immune cells. Studies suggested that transfusions of storage-damaged red cells were likely to cause increased morbidity and mortality. ${ }^{2,8}$ Otherwise, researchers pointed that mortality increased linearly associated with the amount of blood transfused. ${ }^{9,10}$ Most 
studies focused on the index of patients' mortality to assess the clinical effect of blood utilization. ${ }^{11,12}$ The secondary outcomes included complications of pneumonia, adverse reactions and sequentially hospital duration. It can be understandable that in-hospital day's prolongation may make a potential and negative difference on the long-term maintenance of patients.

Primary liver cancer (PLC) is one of the most common malignant tumors worldwide, for which resection surgically and transplantation are the primary choices for the treatment. Due to the rich blood supply and the fragility of the texture, intraoperative bleeding is unavoidable in resection of liver cancer, and clinical transfusion is usually required to correct anemia and maintain the stability of vital signs. Whether perioperative transfusion of red blood cell has a negative effect on patients with PLC by extending in-hospital days remains controversial. ${ }^{13-17}$ Based on this, the aim of our study is to evaluate the impact of transfusion on length of hospital stay (LOHS) in PLC patients who have received perioperative transfusion.

\section{Patients and Methods}

\section{Patients}

The retrospective study included PLC patients who underwent complete liver resection in Hua Shan Hospital of Fudan University of Shanghai, China from December 2015 to December 2018. All of the patients were made a definite diagnosis of PLC by the combination of epidemiologic history, clinical situation, laboratory tests, and imaging examination according to the Asian Pacific Association for the Study of the Liver guideline. We included neither patients who died during the hospitalization or had incomplete documentation within the medical records nor patients less than 18 years old. The study was conducted in accordance with the principles of the Declaration of Helsinki, and the study protocol was approved by the ethics committee of the Clinical Research Ethics Committee of the Huashan Hospital of Fudan University of Shanghai, China. ${ }^{18}$ Because of the retrospective nature of the study, patient consent for inclusion was waived. But patient's personal information was appropriately anonymized and deidentified prior to analysis.

\section{Data Collection and Outcomes}

All of the patients were divided into two groups including perioperative blood transfusion (PBT) and non-PBT groups (Figure 1). All RBCs are prepared in accordance with international standards and supplied by the hospital blood bank according to applicable local regulations. Perioperative blood transfusion was defined as at least 1 unit of allogeneic red blood cell transfusion either during operation or within 24 hours after operation. Blood transfusion during operation was decided according to the institution's clinical protocol ${ }^{19}$ (hemoglobin $<70 \mathrm{~g} / \mathrm{L}$ ). Patients' clinical data were obtained by medical record review within 48 hours after transfusion. Variables included prothrombin time (PT), activated partial thromboplastin time (APTT), fibrinogen, white blood cell (WBC), hemoglobin, hematocrit (hct), neutrocyte, lymphocyte, neutrocyte to lymphocyte ratio (NLR), monocyte, platelet, total bilirubin (tbil), direct bilirubin (dbil), indirect bilirubin (ibil), albumin, globulin, albumin to globulin ratio (AG), albumin/total bilirubin (alb/tbil), albumin/direct bilirubin (alb/ dbil), albumin/indirect bilirubin (alb/ibil). The main study outcomes were the length of hospital stay of patients.

\section{Statistical Analysis}

Data were given as means and SDs for continuous variables and as counts and percentage for categorical variables. The odds ratios (ORs) and corresponding 95\% confidence intervals (CIs) of death in the patients were calculated, respectively, using univariate and multivariate logistic regression analyses. The differences in several groups were compared by independent $t$ test and chisquare test. The data analysis software was SAS for windows version 9.4 (SAS Institute, Cary, NC, USA), IBM SPSS Statistic for windows version 25.0 (SPSS Inc., Armonk, NY, USA) and R for windows (Version 3.4.4). $\mathrm{P}$ values $<0.05$ was considered as statistically significant.

\section{Results \\ The Pathological Baseline of Patients with PLC}

The patient demographics and baseline clinical variables according to transfusion are shown in Table 1. The mean hospital stay was $14.7 \pm 6.5$ days, including $13.9 \pm 5.5$ days for no transfusion group and $17.8 \pm 8.8$ days for transfusion group. Patients receiving perioperative red cell transfusion had increased hospital stay days.

\section{Red Cell Transfusion Prolonged Hospital Stay Days of PLC Patients}

To identify the relationship between transfusion and LOHS, subjects were separated into two groups (Figure 1). Fisher's exact tests revealed that red cell transfusion was associated with the short-term outcomes 


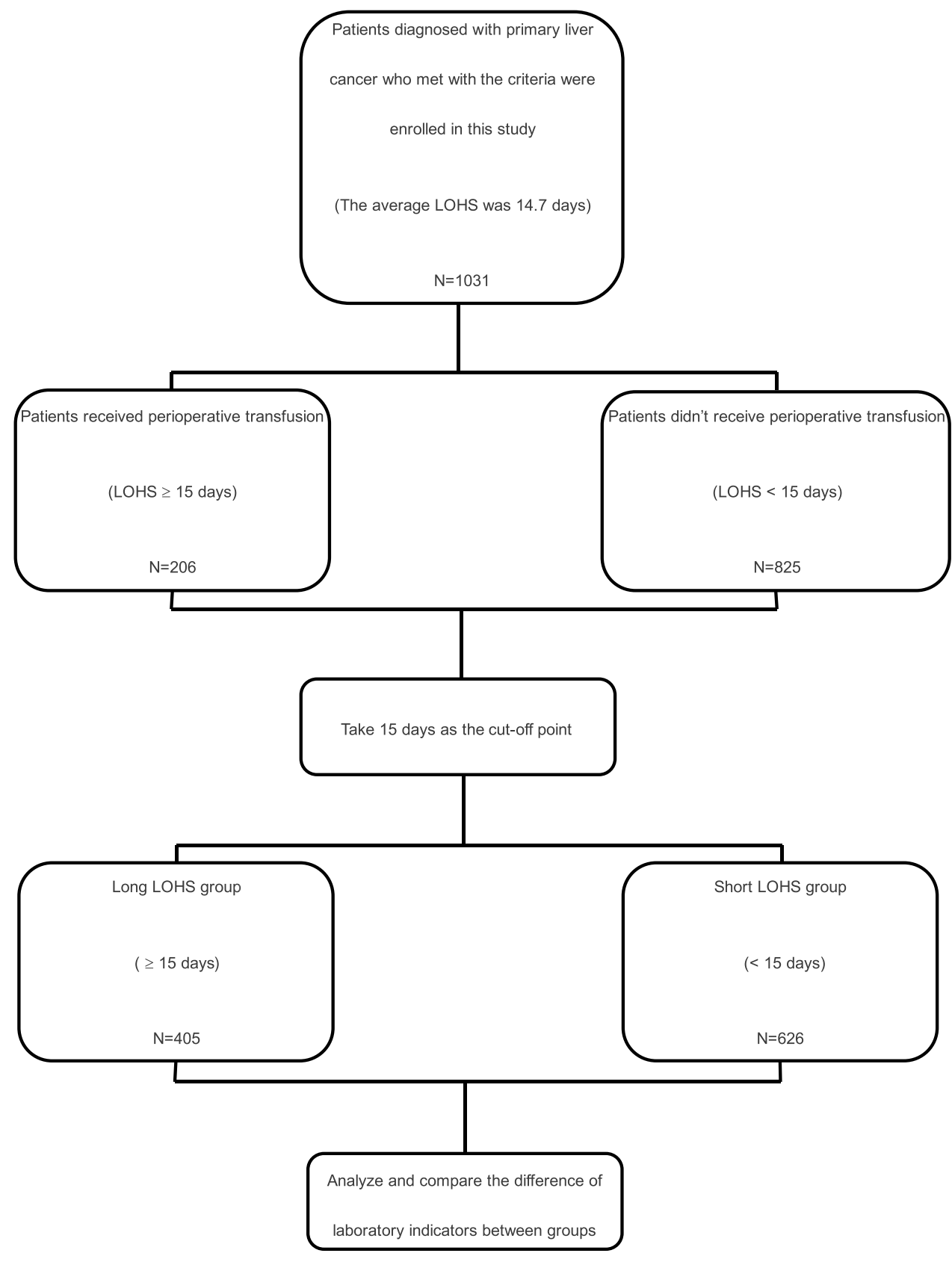

Figure I The flow chart of grouping in the study.

$(p<0.05)$. In the group less than 15 days, $14.1 \%$ of the patients were with RBCs transfusion, compared with $29.1 \%$ of the group over 15 days, which indicated that the proportion of blood transfusion was increased by one time in accordance with the duration in hospital (Table 2).

\section{Relevant Clinical Indicators of the LOHS}

To seek the reason why the transfusion patients' hospital stay days were different from that of the non-transfusion patients', we observed the postoperative indicators related to inflammation and coagulation between different hospital stay groups. The level of postoperative monocytes was the only inflammatory index of statistical difference (7.5 \pm 3.6 vs $7.3 \pm 3.7, p=0.038$ ). These coagulation indicators' significant differences in patients was also detected, including fibrinogen $(2.4 \pm 0.9$ vs $2.6 \pm 1.4, \mathrm{p}<0.001)$, and platelet ( $148.3 \pm 67.6$ vs $159.3 \pm 85.9, p<0.001)$. Besides, we discovered that post contents of several kinds of bilirubin and albumin (alb) were significantly different between the two groups (Table 3 ). 
Table I Patients' Clinicopathological Characteristics

\begin{tabular}{|c|c|c|c|c|}
\hline & Total & PBT Group & None-PBT Group & $P$ value \\
\hline $\mathrm{N}$ & $1031(100.0)$ & $206(20.0)$ & $825(80.0)$ & \\
\hline Age & & & & 0.052 \\
\hline$\leqq 50$ & $339(32.9)$ & $56(5.4)$ & $283(27.4)$ & \\
\hline$>50$ & $692(67.1)$ & $150(14.5)$ & $542(52.6)$ & \\
\hline Gender & & & & 0.136 \\
\hline Male & $777(75.4)$ & I $47(14.3)$ & $630(6 \mathrm{I} .1)$ & \\
\hline Female & $254(24.6)$ & $59(5.7)$ & $195(18.9)$ & \\
\hline BMI & $23.3(3.1)$ & $22.9(3.3)$ & $23.4(3.0)$ & 0.091 \\
\hline Co-illnesses & $132(12.8)$ & $38(3.7)$ & $94(9.1)$ & 0.007 \\
\hline ASA scores & & & & $<0.001$ \\
\hline$\leqq 2$ & $992(96.2)$ & $187(18.1)$ & 805 (78.I) & \\
\hline$>2$ & $39(3.8)$ & $19(1.8)$ & $20(1.9)$ & \\
\hline $\mathrm{HBsAg}(+)$ & $700(68.0)$ & $121(11.7)$ & $579(56.2)$ & 0.002 \\
\hline Anti-HCV (+) & $18(1.7)$ & $8(0.8)$ & $10(1.0)$ & 0.009 \\
\hline Cirrhosis (+) & $661(64.1)$ & $132(12.8)$ & $529(5 \mid .3)$ & 0.991 \\
\hline ECOG performance status & & & & 0.059 \\
\hline 0 & $953(92.4)$ & $184(17.8)$ & $769(74.6)$ & \\
\hline $\mathrm{I}-2$ & $78(7.6)$ & $22(2.1)$ & $56(5.4)$ & \\
\hline Repeat hepatectomy & $186(18.0)$ & $37(3.6)$ & $149(14.5)$ & 0.974 \\
\hline Child-Pugh grade & & & & 0.112 \\
\hline A & $1021(99.0)$ & $202(19.6)$ & $819(79.4)$ & \\
\hline B & $10(1.0)$ & $4(0.4)$ & $6(0.6)$ & \\
\hline TNM stage & & & & $<0.001$ \\
\hline 1 & $370(35.9)$ & $47(4.6)$ & $323(31.3)$ & \\
\hline II & $384(37.2)$ & $86(8.3)$ & $298(28.9)$ & \\
\hline III & $243(23.6)$ & $60(5.8)$ & $183(17.7)$ & \\
\hline IV & $34(3.3)$ & $13(1.3)$ & $21(2.0)$ & \\
\hline Tumor differentiation & & & & 0.272 \\
\hline 1 & $18(1.7)$ & $2(0.2)$ & $16(1.6)$ & \\
\hline II & $691(67.0$ & $129(12.5)$ & $562(54.5)$ & \\
\hline III & $312(30.3)$ & $73(7.1)$ & $239(23.2)$ & \\
\hline IV & $10(1.0)$ & $2(0.2)$ & $8(0.8)$ & \\
\hline Tumor size & & & & $<0.001$ \\
\hline$\leqq 5$ & $689(66.8)$ & $105(10.2)$ & $584(56.6)$ & \\
\hline$>5$ & $342(33.20$ & $101(9.8)$ & $241(23.4)$ & \\
\hline Tumor number & & & & 0.994 \\
\hline Solitary & $836(8 I . I)$ & $167(16.2)$ & 669 (64.9) & \\
\hline Multiple & $195(18.9)$ & $39(3.8)$ & $156(15.1)$ & \\
\hline Satellites & $179(17.4)$ & $57(5.5)$ & $122(1 \mid .8)$ & $<0.001$ \\
\hline Extent of hepatectomy & & & & $<0.001$ \\
\hline Minor & $764(74.1)$ & $120(11.6)$ & $644(52.5)$ & \\
\hline Major & $267(25.9)$ & $86(8.3)$ & I8I (17.6) & \\
\hline
\end{tabular}

(Continued) 
Table I (Continued).

\begin{tabular}{|l|c|c|c|c|}
\hline & Total & PBT Group & None-PBT Group & P value \\
\hline Pringle maneuver & $423(41.0)$ & $76(7.4)$ & $347(33.7)$ & 0.177 \\
\hline Vascular invasion & $120(11.6)$ & $34(3.3)$ & $86(8.3)$ & 0.015 \\
\hline Portal hypertension (+) & $101(9.8)$ & $35(3.4)$ & $66(6.4)$ & $<0.001$ \\
\hline Hospital-stay days & $14.7(6.5)$ & $17.8(8.8)$ & $13.9(5.5)$ & $<0.001$ \\
\hline Intraoperative blood loss, $\mathrm{mL}$ & $389.7(421.1)$ & $820.2(693.0)$ & $282.2(209.7)$ & $<0.001$ \\
\hline
\end{tabular}

Notes: Co-illnesses: comorbid illnesses include hypertension, diabetes, cardiovascular disease, appendicitis, cholecystitis and renal dysfunction.

Abbreviations: BMI, body mass index; ECOG, Eastern Cooperative Oncology Group; HBsAg, hepatitis B surface antigen; HCV, hepatitis C virus;.

Table 2 The Relationship Between Transfusion and Hospital Duration

\begin{tabular}{|l|c|c|c|c|c|}
\hline & \multicolumn{2}{|c|}{ LOHS < I5 Days } & \multicolumn{2}{c|}{ LOHS $\geq$ I5 Days } & P value \\
\hline & Number & Percentage Within LOHS Group & Number & Percentage Within LOHS Group & \\
\hline Transfusion & 88 & $14.1 \%$ & 118 & $29.1 \%$ & $<0.05$ \\
Non-transfusion & 538 & $85.9 \%$ & 287 & $70.9 \%$ & $<0.05$ \\
Total & 626 & $100.0 \%$ & 405 & $100.0 \%$ & $<0.05$ \\
\hline
\end{tabular}

Table 3 Comparisons of Patients' Postoperative Parameters Between the Different Hospital Stays Groups

\begin{tabular}{|l|c|c|c|c|}
\hline & Total & $\begin{array}{c}\text { Hospital } \\
\text { Stays }<\text { I5 } \\
\text { Days }\end{array}$ & $\begin{array}{c}\text { Hospital } \\
\text { Stays } \geq \text { I5 } \\
\text { Days }\end{array}$ & P value \\
\hline PT, s & $13.8(9.1)$ & $13.6(9.1)$ & $14.2(9.2)$ & 0.806 \\
APTT, s & $31.8(13.0)$ & $31.2(11.8)$ & $32.7(14.7)$ & 0.048 \\
Fibrinogen, g/L & $2.5(1.1)$ & $2.4(0.9)$ & $2.6(1.4)$ & $<0.001$ \\
WBC & $16.5(74.8)$ & $14.9(42.2)$ & $18.8(107.0)$ & 0.210 \\
Hemoglobin, g/L & $121.7(20.7)$ & $123.3(20.1)$ & $119.2(21.3)$ & 0.132 \\
Hct & $38.3(21.3)$ & $38.3(20.1)$ & $38.4(23.0)$ & 0.330 \\
Neutrocyte & $85.9(26.2)$ & $86.3(33.3)$ & $85.4(7.2)$ & 0.522 \\
Lymphocyte & $7.4(5.0)$ & $7.5(4.4)$ & $7.1(5.7)$ & 0.178 \\
NLR & $16.4(12.7)$ & $16.1(13.4)$ & $16.8(11.6)$ & 0.732 \\
Monocyte & $7.4(3.6)$ & $7.5(3.5)$ & $7.3(3.7)$ & 0.038 \\
Platelet count, $\times 10^{9} / L$ & $152.7(75.5)$ & $148.3(67.6)$ & $159.3(85.9)$ & $<0.001$ \\
Tbil & $27.6(37.8)$ & $23.5(23.7)$ & $33.9(52.0)$ & $<0.001$ \\
Dbil & $14.6(29.3)$ & $11.3(18.7)$ & $19.6(40.0)$ & $<0.001$ \\
Ibil & $12.9(11.7)$ & $12.1(8.8)$ & $14.1(15.0)$ & $<0.001$ \\
Albumin, g/L & $36.6(4.4)$ & $37.1(4.3)$ & $35.8(4.6)$ & 0.02 \\
Globulin, g/L $\dagger$ & $23.6(8.3)$ & $24.0(9.8)$ & $22.8(5.3)$ & 0.458 \\
AG & $1.6(0.4)$ & $1.6(0.4)$ & $1.6(0.4)$ & 0.105 \\
Alb/Tbil & $2.0(1.0)$ & $2.1(1.0)$ & $1.8(0.9)$ & 0.934 \\
Alb/Dbil & $4.4(2.6)$ & $4.7(2.6)$ & $4.0(2.7)$ & 0.831 \\
Alb/lbil & $3.4(11.4)$ & $3.3(14.5)$ & $3.6(1.9)$ & 0.525 \\
\hline
\end{tabular}

To further confirm the independent factor for LOHS, we used univariate and multivariate regression analysis as follows (Table 4). The data suggested that perioperative RBCs transfusion did impact the patients' hospital stay days. Meanwhile, the results showed that the indicators of total bilirubin (tbil), indirect bilirubin (ibil), and the ratio of albumin to total bilirubin (alb/tbil) and albumin to indirect bilirubin (alb/ibil) could be used to estimate the LOHS of PLC patients.

\section{Transfusion Has an Effect on Hospital Stay Days Probably Through Affecting Functional Indexes}

To explain the cause of why transfusion led to prolong patients' hospital duration, we evaluated clinical laboratory test results between the transfusion and nontransfusion groups (Table 5). Significant differences existed among the postoperative factors of APTT, fibrinogen, hct, neutrocyte to lymphocyte ratio (NLR), monocyte, platelet, tbil, dbil, ibil, alb, the albumin and globulin ratio (AG), the albumin and direct bilirubin ratio (alb/dbil) between the two groups (all $p<0.05$ ). This suggests that the intrinsic coagulation pathway and inflammatory index were changed in patients receiving a transfusion. Transfusion also affect bilirubin levels, which are independent factors for LOHS.

\section{Discussion}

Primary liver cancer (PLC) is one of the most common tumors worldwide. $^{20}$ In China, the annual incidence and mortality of PLC are estimated to continue to increase. ${ }^{21}$ Although surgical resection and transplantation are the 
Table 4 Univiarate and Multivariate Analysis of LOHS

\begin{tabular}{|c|c|c|c|c|}
\hline \multirow[t]{2}{*}{ Variables } & \multicolumn{2}{|c|}{ Univariate Analysis } & \multicolumn{2}{|c|}{ Multivariate Analysis } \\
\hline & Hazard Ratio $(95 \% \mathrm{Cl})$ & HR P value & Hazard Ratio (95\% Cl) & HR $P$ value \\
\hline PT, s & I.007 (0.993-I.02I) & 0.335 & $1.005(0.99 \mid-1.020)$ & 0.493 \\
\hline APTT, s & $1.010(0.997-1.024)$ & 0.139 & $1.004(0.994-1.014)$ & 0.458 \\
\hline Fibrinogen, $g / L$ & $1.131(1.001-1.278)$ & 0.049 & $1.136(0.982-1.315)$ & 0.087 \\
\hline WBC & 1.001 (0.999-1.003) & 0.451 & 1.001 (0.999-1.003) & 0.338 \\
\hline Hemoglobin, g/L & $0.990(0.984-0.996)$ & 0.002 & $0.997(0.990-1.005)$ & 0.494 \\
\hline $\mathrm{Hct}$ & $1.000(0.994-1.006)$ & 0.961 & 1.001 (0.995-1.008) & 0.719 \\
\hline Neutrocyte & $0.998(0.992-1.005)$ & 0.616 & $0.993(0.968-1.019)$ & 0.599 \\
\hline Lymphocyte & $0.983(0.955-1.011)$ & 0.223 & $0.990(0.954-1.028)$ & 0.604 \\
\hline NLR & $1.005(0.995-1.015)$ & 0.376 & $1.002(0.985-1.020)$ & 0.824 \\
\hline Monocyte & $0.986(0.949-1.024)$ & 0.468 & $0.988(0.949-1.028)$ & 0.550 \\
\hline Platelet count, $\times 109 / \mathrm{L}$ & $1.002(1.000-1.004)$ & 0.026 & $1.002(1.000-1.004)$ & 0.048 \\
\hline Tbil & $1.010(1.005-1.006)$ & $<0.001$ & $1.013(1.005-1.021)$ & 0.002 \\
\hline Dbil & $1.013(1.006-1.021)$ & $<0.001$ & $0.990(0.970-1.010)$ & 0.307 \\
\hline lbil & $1.017(1.003-1.030)$ & 0.013 & $1.013(1.005-1.021)$ & 0.001 \\
\hline Albumin, $g / L$ & $0.934(0.906-0.963)$ & $<0.001$ & $0.978(0.934-1.024)$ & 0.335 \\
\hline Globulin, g/L & $0.968(0.946-0.992)$ & 0.008 & $0.955(0.909-1.002)$ & 0.062 \\
\hline AG & $1.034(0.735-1.454)$ & 0.849 & $0.828(0.383-1.791)$ & 0.631 \\
\hline Alb/Tbil & $0.701(0.608-0.809)$ & $<0.001$ & $0.483(0.265-0.880)$ & 0.017 \\
\hline Alb/Dbil & $0.881(0.835-0.931)$ & $<0.001$ & $1.069(0.934-1.223)$ & 0.331 \\
\hline Alb/lbil & $1.003(0.989-1.017)$ & 0.667 & $1.235(1.021-1.492)$ & 0.029 \\
\hline Transfusion & $0.400(0.292-0.547)$ & $<0.001$ & $0.566(0.395-0.81 \mathrm{I})$ & 0.002 \\
\hline
\end{tabular}

Table 5 Comparisons of Patients' Postoperative Parameters Between PBT and Non-PBT Groups

\begin{tabular}{|c|c|c|c|c|}
\hline & Total & PBT Group & None-PBT Group & $P$ value \\
\hline PT, s & $13.8(9.1)$ & $14.6(8.6)$ & $13.7(9.2)$ & 0.678 \\
\hline APTT, s & $31.2(6.1)$ & $35.2(19.2)$ & $30.9(10.7)$ & 0.002 \\
\hline Fibrinogen, g/L & $2.5(1.1)$ & $2.5(1.7)$ & $2.5(0.9)$ & $<0.001$ \\
\hline WBC & I $6.5(74.8)$ & $13.9(5.9)$ & I7.I (83.9) & 0.425 \\
\hline Hemoglobin, g/L & $121.7(20.7)$ & $110.2(19.5)$ & $124.6(20.0)$ & 0.652 \\
\hline Hct & $38.3(21.3)$ & $37.3(31.2)$ & $38.6(17.6)$ & 0.011 \\
\hline Neutrocyte & $85.9(26.2)$ & $86.8(6.1)$ & $85.7(29.3)$ & 0.53 \\
\hline Lymphocyte & $7.4(5.0)$ & $6.5(6.7)$ & $7.6(4.4)$ & 0.398 \\
\hline NLR & $16.4(12.7)$ & $19.3(12.5)$ & $15.6(12.7)$ & 0.038 \\
\hline Monocyte & $7.4(3.6)$ & $7.3(5.0)$ & $7.5(3.1)$ & 0.038 \\
\hline Platelet count, $\times 10^{9} / \mathrm{L}$ & $152.7(75.4)$ & I $50.3(92.2)$ & I53.3 (70.6) & 0.001 \\
\hline Tbil & $27.6(37.8)$ & $41.8(63.6)$ & $23.9(26.6)$ & $<0.001$ \\
\hline Dbil & $14.6(29.3)$ & $24.5(48.4)$ & $12.1(21.1)$ & $<0.001$ \\
\hline lbil & $12.9(11.7)$ & $17.0(19.0)$ & $11.9(8.6)$ & $<0.001$ \\
\hline Albumin, $g / L$ & $36.6(4.4)$ & $34.4(5.0)$ & $37.2(4.1)$ & $<0.001$ \\
\hline Globulin, g/L † & $23.6(8.3)$ & $22.7(6.6)$ & $23.8(8.7)$ & 0.093 \\
\hline AG & I.6 (0.4) & I.6 (0.45) & I.6 (0.34) & $<0.001$ \\
\hline Alb/Tbil & $2.0(1.0)$ & I.4 (0.9) & $2.1(1.0)$ & 0.061 \\
\hline Alb/Dbil & $4.4(2.6)$ & $3.1(2.3)$ & $4.8(2.6)$ & 0.001 \\
\hline Alb/lbil & 3.4 (II.4) & 3.1 (1.9) & $3.5(12.7)$ & 0.587 \\
\hline
\end{tabular}

main treatment options, it is still a challenge with a high risk of massive blood loss. And the long-term prognosis remains unsatisfactory because of recurrence and metastasis after curative resection. ${ }^{22}$ The outcome is reported to be influenced probably by many clinical factors, such as liver cirrhosis, tumor size, surgical margin, 
vascular invasion and perioperative blood transfusion. ${ }^{23,24}$ PBT has already been reported to negatively affects survival time of patients in many neoplasms. ${ }^{25-29}$

The current study showed a clear connection between PBT and in-hospital days in PLC, and found that transfusion prolonged in-hospital days. Multivariate regression analysis demonstrates the LOHS is related to serum tbil, ibil, alb/tbil, $\mathrm{alb} / \mathrm{ibil}$ and transfusion. Researchers have pointed that elevated bilirubin could lead to irreversible damage to the brains and neurons, especially the increased indirect bilirubin with strong toxicity. ${ }^{30,31}$ And the bilirubin-albumin ratio level was related to the bilirubin encephalopathy, which could be a potential predictor in neonates' patients. The imbalance of oxidation and antioxidation is associated with varieties of inflammatory conditions. ROS may promote the release of inflammatory cytokines, which may weaken antioxidant defenses and lead to oxidative stress. It was reported that Ibil exerted anti-ROS properties. Thus, we suppose that bilirubin as endogenous antioxidants which have been shown to inhibit the production of proinflammatory cytokine, ${ }^{32}$ and therefore had protective effects. ${ }^{33}$ Bilirubin may be over-consumed and destructed during the inflammatory process and due to prolong inhospital days.

To further explain why RBCs transfusion leads to prolonged in-hospital days, we estimated postoperative clinical laboratory parameters. When patients were given perioperative RBCs transfusion, the time of APTT increased, the levels of fibrinogen changed and the amount of platelet decreased respectively. This suggested that the transfused red blood cell had certain effects on coagulation function. ${ }^{34}$ The altered NLR and the quantity of monocyte showed that PLC patients inclined to get bacterial infection and the immune defense weakened, ${ }^{35}$ which probably caused longer hospital stays in the PBT group. Besides, other different post indicators including all kinds of bilirubin, albumin, albumin/ globulin and albumin/bilirubin indicated the degree of liver function recovery and Impaired renal function after RBCs transfusion. ${ }^{36}$ As we all know, after the rupture of red blood cells transfused in spleens, heme is released to bind the globin in serum and thus transform into indirect bilirubin. ${ }^{37}$ The more red blood cells are destroyed, the more indirect bilirubin with toxicity. The decreased albumin showed impaired liver function and the less ability to detoxify. In our study, both the levels of bilirubin and bilirubinalbumin ratio changed a lot in different hospital duration or transfusion groups. This may provide a new perspective on that transfusion could impact the in-hospital days of PLC patients through changing bilirubin and albumin in plasma.
However, the results may not be generalized to all of the liver cancers due to several potential limitations in our study. First, the retrospective nature determines it is not a randomized controlled trial and all of the data were come from a single medical center. Second, although 1031 patients underwent curative liver resection in this study, only 206 of them received red blood cell transfusion, and the small sample size limited us from drawing conclusions about the correlation between transfusion and in-hospital maintenance. Thus, a large-scale prospective study in multicenter is needed for further confirmation.

In conclusion, the relationship between transfused RBCs transfusion and the length of hospital stays of PLC patients after curative resection was evaluated in this retrospective study. We found that transfusion prolonged inhospital maintenance of patients with primary liver cancer via changing intrinsic coagulation and inflammatory factors and bilirubin levels in plasma.

\section{Acknowledgments}

The present study is supported by National Natural Science Foundation of China (81570166 and 81670173).

\section{Disclosure}

The authors report no conflicts of interest in this work.

\section{References}

1. Uhl L. Patient blood management: a 68-year-old woman contemplating autologous blood donation before elective surgery. JAMA. 2011;306(17):1902-1910. doi:10.1001/jama.2011.1526

2. Lelubre C, Piagnerelli M, Vincent JL. Association between duration of storage of transfused red blood cells and morbidity and mortality in adult patients: myth or reality? Transfusion. 2009;49(7):1384-1394. doi:10.1111/j.1537-2995.2009.02211.x

3. Docherty AB, Walsh TS. Anemia and blood transfusion in the critically ill patient with cardiovascular disease. Crit Care. 2017;21(1):61. doi:10.1186/s13054-017-1638-9

4. Goubran H, Sheridan D, Radosevic J, Burnouf T, Seghatchian J. Transfusion-related immunomodulation and cancer. Transfus Apher Sci. 2017:S1473050217301039.

5. Kuldanek S, Silliman CC. Mortality after red blood cell transfusions from previously pregnant donors: complexities in the interpretation of large data. $J$ Thorac Dis. 2018;10(2):648-652. doi:10.21037/ jtd.2018.01.77

6. Yoshida T, Prudent M, D'Alessandro A. Red blood cell storage lesion: causes and potential clinical consequences. Blood Transfus. 2019;17 (1):27-52. doi:10.2450/2019.0217-18

7. Sparrow RL. Red blood cell storage and transfusion-related immunomodulation. Blood Transfus. 2010;8 Suppl 3(Suppl3):s26-30. doi: $10.2450 / 2010.005 \mathrm{~s}$

8. Robinson WP 3rd, Ahn J, Stiffler A, et al. Blood transfusion is an independent predictor of increased mortality in nonoperatively managed blunt hepatic and splenic injuries. $J$ Trauma. 2005;58(3):437-44; discussion 444-5. doi:10.1097/01.ta.0000153935.18997.14 
9. Malone DL, Dunne J, Tracy JK, Putnam AT, Scalea TM, Napolitano LM. Blood transfusion, independent of shock severity, is associated with worse outcome in trauma. J Trauma. 2003;54 (5):898-905; discussion 905-7. doi:10.1097/01.Ta.00000602 $61.10597 .5 \mathrm{c}$

10. Shander A, Hofmann A, Gombotz H, Theusinger OM, Spahn DR. Estimating the cost of blood: past, present, and future directions. Best Pract Res Clin Anaesthesiol. 2007;21(2):271-289. doi:10.1016/j. bpa.2007.01.002

11. Irving AH, Harris A, Petrie D, Higgins A, Smith J, McQuilten ZK. Impact of patient blood management guidelines on blood transfusions and patient outcomes during cardiac surgery. $J$ Thorac Cardiovasc Surg. 2020;160(2):437-445.e20. doi:10.1016/j.jtcvs.2019.08.102

12. Stanworth SJ, Killick S, McQuilten ZK, et al. Red cell transfusion in outpatients with myelodysplastic syndromes: a feasibility and exploratory randomised trial. Br J Haematol. 2020;189(2):279-290. doi:10.1111/bjh.16347

13. Latchana N, Hirpara DH, Hallet J, Karanicolas PJ. Red blood cell transfusion in liver resection. Langenbecks Arch Surg. 2019;404 (1):1-9. doi:10.1007/s00423-018-1746-2

14. Kwon JH, Han S, Cho D, et al. Longer storage of red blood cells does not affect mortality in transfused liver transplant recipients. Transfusion. 2018;58(11):2529-2537. doi:10.1111/trf.14961

15. Dunn LK, Thiele RH, Ma JZ, Sawyer RG, Nemergut EC. Duration of red blood cell storage and outcomes following orthotopic liver transplantation. Liver Transpl. 2012;18(4):475-481. doi:10.1002/ 1t.23379

16. Chen J, Singhapricha T, Memarzadeh M, et al. Storage age of transfused red blood cells during liver transplantation and its intraoperative and postoperative effects. World J Surg. 2012;36 (10):2436-2442. doi:10.1007/s00268-012-1691-0

17. Cywinski JB, You J, Argalious M, et al. Transfusion of older red blood cells is associated with decreased graft survival after orthotopic liver transplantation. Liver Transpl. 2013;19(11):1181-1188. doi:10.1002/lt.23695

18. Liaw YF, Kao JH, Piratvisuth T, et al. Erratum to: Asian-Pacific consensus statement on the management of chronic hepatitis B: a 2012 update. Hepatol Int. 2012;6(4):809-810. doi:10.1007/ s12072-012-9386-z

19. Anesthesiology branch of Chinese Medical Association. Chinese Anesthesiology Guidelines and Expert Consensus. People's Medical Publishing House; 2014.

20. Siegel R, Ma J, Zou Z, Jemal A. Cancer statistics, 2014. CA Cancer J Clin. 2014;64(1):9-29. doi:10.3322/caac.21208

21. Chen W, Zheng R, Baade PD, et al. Cancer statistics in China, 2015. CA Cancer J Clin. 2016;66(2):115-132. doi:10.3322/caac.21338

22. Bruix J, Gores GJ, Mazzaferro V. Hepatocellular carcinoma: clinical frontiers and perspectives. Gut. 2014;63(5):844-855. doi:10.1136/ gutjnl-2013-306627

23. Huang G, Lau WY, Zhou WP, et al. Prediction of hepatocellular carcinoma recurrence in patients with low hepatitis B virus DNA levels and high preoperative hepatitis B surface antigen levels. JAMA Surg. 2014;149(6):519-527. doi:10.1001/jamasurg.2013.4648
24. Han DH, Choi GH, Park JY, et al. Lesson from 610 liver resections of hepatocellular carcinoma in a single center over 10 years. World J Surg Oncol. 2014;12:192. doi:10.1186/1477-7819-12-192

25. Abe T, Amano H, Hanada K, et al. Perioperative red blood cell transfusion is associated with poor long-term survival in pancreatic adenocarcinoma. Anticancer Res. 2017;37(10):5863-5870. doi:10.21873/anticanres.12031

26. Amri R, Dinaux AM, Leijssen LGJ, Kunitake H, Bordeianou LG, Berger DL. Do packed red blood cell transfusions really worsen oncologic outcomes in colon cancer? Surgery. 2017;162 (3):586-591. doi:10.1016/j.surg.2017.03.024

27. Gui R, Tang H, Gao M, et al. Impact of perioperative blood transfusion on survival of patients undergoing laparoscopic gastrectomy for gastric cancer. J buon. 2017;22(2):396-402.

28. Kluth LA, Xylinas E, Rieken M, et al. Impact of peri-operative blood transfusion on the outcomes of patients undergoing radical cystectomy for urothelial carcinoma of the bladder. BJU Int. 2014;113 (3):393-398. doi:10.1111/bju.12439

29. Liu L, Wang Z, Jiang S, et al. Perioperative allogenenic blood transfusion is associated with worse clinical outcomes for hepatocellular carcinoma: a meta-analysis. PLoS One. 2013;8(5):e64261. doi:10.1371/journal.pone.0064261

30. Wang Y, Sheng G, Shi L, Cheng X. Increased serum total bilirubin-albumin ratio was associated with bilirubin encephalopathy in neonates. Biosci Rep. 2020;40(1). doi:10.1042/bsr20192152

31. Li J, Zhao L, Wang Z, Zhao X, Wu J. Association of serum indirect bilirubin concentrations with motor subtypes of Parkinson's disease. Neurodegener Dis. 2019;19(3-4):155-162. doi:10.1159/000505852

32. Su Q, Li X, Mo W, Yang Z. Low serum bilirubin, albumin, and uric acid levels in patients with Crohn's disease. Medicine (Baltimore). 2019;98(19):e15664. doi:10.1097/md.0000000000015664

33. Qin XL, Zhang QS, Sun L, Hao MW, Hu ZT. Lower serum bilirubin and uric acid concentrations in patients with Parkinson's disease in China. Cell Biochem Biophys. 2015;72(1):49-56. doi:10.1007/ s12013-014-0402-x

34. Northup P, Reutemann B. Management of coagulation and anticoagulation in liver transplantation candidates. Liver Transpl. 2018;24(8):1119-1132. doi:10.1002/1t.25198

35. Dragan D, Goran R, Maja S, et al. Neutrophil-to-lymphocyte ratio, monocyte-to-lymphocyte ratio, platelet-to-lymphocyte ratio, and mean platelet volume-to-platelet count ratio as biomarkers in critically Ill and injured patients: which ratio to choose to predict outcome and nature of bacter. Mediators Inflamm. 2018;15. doi:10.1155/ 2018/3758068

36. Feng $\mathrm{D}$, Wang $\mathrm{M}$, $\mathrm{Hu} \mathrm{J}$, et al. Prognostic value of the albumin-bilirubin grade in patients with hepatocellular carcinoma and other liver diseases. Ann Transl Med. 2020;8(8):553. doi:10.21037/atm.2020.02.116

37. Pietropaoli AP, Henrichs KF, Cholette JM, et al. Total plasma heme concentration increases after red blood cell transfusion and predicts mortality in critically ill medical patients. Transfusion. 2019;59 (6):2007-2015. doi:10.1111/trf.15218

\section{Publish your work in this journal}

Cancer Management and Research is an international, peer-reviewed open access journal focusing on cancer research and the optimal use of preventative and integrated treatment interventions to achieve improved outcomes, enhanced survival and quality of life for the cancer patient.
The manuscript management system is completely online and includes a very quick and fair peer-review system, which is all easy to use. Visit http://www.dovepress.com/testimonials.php to read real quotes from published authors. 